\title{
Optimization of the squid giant axon leak conductance for repetitive firing
}

\author{
Patrick Crotty \\ From Nineteenth Annual Computational Neuroscience Meeting: CNS*2010 \\ San Antonio, TX, USA. 24-30 July 2010
}

Recent work [1] indicates that the leak conductance $\left(G_{L}\right)$ in the squid giant axon is optimal for the action potential firing frequency. Assuming a chloride leak current, the measured $G_{L}$ of approximately $0.3 \mathrm{mS} / \mathrm{cm}^{2}$ is very close to the theoretical optimal value that minimizes the absolute refractory period, or equivalently, that maximizes the highest frequency at which action potentials can be generated. These results were obtained by simulating brief, sharp current injections at one end of a Hodgkin-Huxley axon model, consistent with the standard experimental technique for measuring refractory periods. However, it is known [2] that constant current inputs to one end of a spatially axon can also evoke repetitive firing over a relatively narrow range of input strength. We have therefore investigated the optimality of $G_{L}$ for constant input currents $\left(I_{D C}\right)$. We find that the repetitive firing frequency is indeed maximized near biological values of $G_{L}$ for lower values of $I_{D C}$ (Figure 1). However, at higher values of $I_{D C}$, the frequency-optimal $G_{L}$ goes to 0 , and the firing frequency itself is even higher. Thus, solely from the point of view of maximizing repetitive firing frequency under constant current input, the combination of a high input current strength and little to no leak conductance would seem best. However, when one takes temperature into account, it suggests why evolution has not chosen this strategy. The ocean temperatures which a cold-blooded squid encounters can vary by as much as 10 degrees Celsius over a few months [3]. The repetitive firing of the axon therefore must be able to function over such a range. As shown in Figure 2, the range of $G_{L}-I_{D C}$ parameter space over which repetitive firing can occur shrinks dramatically with increasing temperature. Since the value of $G_{L}$ is presumably unchangeable, the configuration which

Correspondence: pcrotty@colgate.edu

Department of Physics and Astronomy, Colgate University, Hamilton, NY 13346, USA

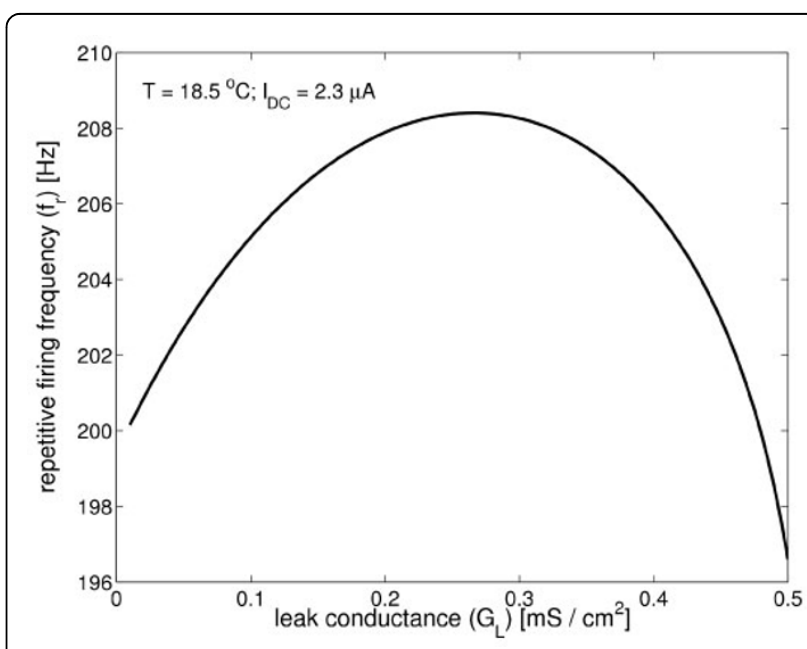

Figure 1 Repetitive firing frequency as function of leak conductance for a specific input current strength.

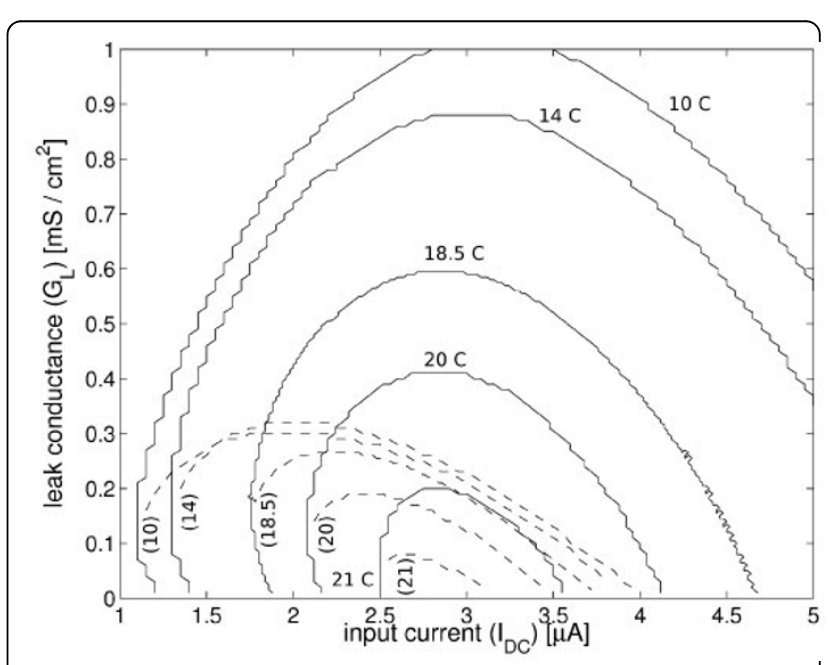

Figure 2 Solid curves: boundaries in $G_{L} I_{D C}$ phase space outside of which repetitive firing is not possible under constant current input. Dashed curves: optimal $G_{L}$ values for each $I_{D C}$ 
best preserves the ability of the axon to repetitively fire over the largest range of temperature favors $G_{L}$ values near the biological value.

Published: 20 July 2010

\section{References}

1. Seely J, Crotty P: Optimization of the leak conductance in the squid giant axon. 2000 [http://arxiv.org/abs/0905.3154].

2. Rinzel J: Repetitive activity and Hopf bifurcation under point-stimulation for a simple FitzHugh-Nagumo nerve conduction model. J. Math. Biology 1978, 5:363-382.

3. Rosenthal JJC, Bezanilla F: Seasonal variation in conduction velocity of action potentials in squid giant axons. Biol. Bull. 2000, 199:135-143.

doi:10.1186/1471-2202-11-S1-P138

Cite this article as: Crotty: Optimization of the squid giant axon leak conductance for repetitive firing. BMC Neuroscience 2010 11(Suppl 1): P138.

Submit your next manuscript to BioMed Central and take full advantage of:

- Convenient online submission

- Thorough peer review

- No space constraints or color figure charges

- Immediate publication on acceptance

- Inclusion in PubMed, CAS, Scopus and Google Scholar

- Research which is freely available for redistribution

Submit your manuscript at www.biomedcentral.com/submit 